\title{
Expression of nerve growth factor and heme oxygenase-1 predict poor survival of breast carcinoma patients
}

\author{
Sang Jae Noh', Jun Sang Bae', Urangoo Jamiyandorj ${ }^{1}$, Ho Sung Park', Keun Sang Kwon², Sung Hoo Jung ${ }^{3}$, \\ Hyun Jo Youn ${ }^{3}$, Ho Lee ${ }^{4}$, Byung-Hyun Park ${ }^{5}$, Myoung Ja Chung ${ }^{1}$, Woo Sung Moon ${ }^{1}$, Myoung Jae Kang ${ }^{1}$ \\ and Kyu Yun Jang ${ }^{1 *}$
}

\begin{abstract}
Background: Nerve growth factor (NGF) is a neurotrophin and has been suggested to induce heme oxygenase-1 (HO1) expression. Although the role of $\mathrm{HO} 1$ in tumorigenesis remains controversial, recent evidence suggests NGF and $\mathrm{HO} 1$ as tumor-progressing factors. However, the correlative role of NGF and $\mathrm{HO} 1$ and their prognostic impact in breast carcinoma is unknown.
\end{abstract}

Methods: We investigated the expression and prognostic significance of the expression of NGF and HO1 in 145 cases of breast carcinoma.

Results: Immunohistochemical expression of NGF and HO1 was observed in 31\% and 49\% of breast carcinoma, respectively. The expression of NGF and $\mathrm{HO} 1$ significantly associated with each other, and both have a significant association with histologic grade, HER2 expression, and latent distant metastasis. The expression of NGF and HO1 predicted shorter overall survival of breast carcinoma by univariate and multivariate analysis. NGF expression was an independent prognostic indicator for relapse-free survival by multivariate analysis. The combined expression pattern of NGF and $\mathrm{HO} 1$ was also an independent prognostic indicator of overall survival and relapse-free survival. The patients with tumors expressing NGF had the shortest survival and the patients with tumor, which did not express NGF or HO1 showed the longest survival time.

Conclusions: This study has demonstrated that individual expression of NGF or HO1, and the combined NGF/HO1 expression pattern could be prognostic indicators for breast carcinoma patients.

Keywords: Nerve growth factor, Heme oxygenase-1, Carcinoma, Breast

\section{Background}

Nerve growth factor (NGF) is a neurotrophin, which shows neurotrophic activity on central and peripheral neuronal cells, and exerts variable effects on non-neuronal cells [1]. In addition to its neurotrophic effect, NGF is also known as a stimulator of cancer cell proliferation and tumor angiogenesis, and participates in tumor cell growth and invasion [1-3]. NGF is involved in the development and progression of many tumors of neural origin and epithelial tumors such

\footnotetext{
* Correspondence: kyjang@chonbuk.ac.kr

'Departments of Pathology, Research Institute of Clinical Medicine and Research Institute for Endocrine Sciences, Chonbuk National University Medical School, Jeonju, Republic of Korea

Full list of author information is available at the end of the article
}

as medulloblastoma, glioma, neuroblastoma, melanoma, pancreas cancer, prostate cancer, and breast carcinoma (BRCA) [1-4]. The main function of NGF is mediated by two membranes binding receptors: high affinity tyrosine kinase receptor TrkA and low affinity p $75^{\text {NTR }}$ [1-3]. In BRCA, NGF is shown to act as a mitogen for cancer cells through phosphorylation of TrkA, and it promotes survival and proliferation of cancer cells [2]. The expression of the NGF receptor (NGFR) TrkA enhanced the tumorigenic potential of BRCA in an animal model [5]. In addition, because blocking of NGF pathway was shown to have tumor-suppressive effects in BRCA, NGF was suggested as a potential therapeutic target for the treatment of BRCA [6-8].

\section{Ciomed Central}

(c) 2013 Noh et al.; licensee BioMed Central Ltd. This is an open access article distributed under the terms of the Creative Commons Attribution License (http://creativecommons.org/licenses/by/2.0), which permits unrestricted use, distribution, and reproduction in any medium, provided the original work is properly cited. 
Heme oxygenase-1 (HO1) is an enzyme that catalyzes heme breakdown, generating free iron, carbon monoxide, and bilirubin [9]. Because of the combined effect of its products, $\mathrm{HO} 1$ acts as a strong antioxidant with antiinflammatory, anti-apoptotic, and immunomodulatory effects $[10,11]$. Therefore, $\mathrm{HO} 1$ is protective against various injuries, such as necrotizing enterocolitis [11] and ischemic-reperfusion injury [12]. However, anti-apoptotic and cytoprotective roles for chemotherapeutic agents targeting $\mathrm{HO} 1$ were shown to induce tumor-progression [13-15]. Increased expression of HO1 in malignant tissue compared with normal tissue has been reported in various human malignant tumors, such as prostate cancer [16], oral squamous cell carcinoma [17], and lung cancers $[18,19]$. However, there are conflicting reports regarding the prognostic role of $\mathrm{HO} 1$ in human malignant tumors. High expression of $\mathrm{HO} 1$ is associated with poor prognosis of non-small cell lung cancer [18]. In contrast, HO1 expression is associated with favorable prognosis of colorectal cancer patients [20] and low risk of lymph node metastasis in oral squamous cell carcinoma [21]. Therefore, the role of $\mathrm{HO} 1$ in human malignant tumors still remains controversial.

Increasing evidence suggests that NGF and HO1 are involved in tumorigenesis and could therefore be possible therapeutic targets of human malignant tumors. However, there are no previous reports examining the clinical significance of the expression of NGF itself in BRCA patients. In addition, both NGF and HO1 exert neuroprotective effects, and NGF induces HO1 expression via mitogen-activated protein kinase kinase activation [22] or in a phosphatidylinositol 3-kinase-dependent manner [23]. Therefore, there is a possibility that NGF and HO1 are cooperatively involved in the tumorigenesis via their roles in cellular adaptation to stress and resistance to apoptosis. However, the relationship between NGF and $\mathrm{HO} 1$ and the role of $\mathrm{HO} 1$ in cancer progression is still unclear in BRCA. Therefore, this study investigated the correlation between the expression of NGF and HO1 and their prognostic impact in BRCA.

\section{Methods}

\section{Patients and tissue samples}

One hundred and forty-five paraffin-embedded tissue samples from female BRCA patients who underwent wide local excision or modified radical mastectomy in Chonbuk National University Hospital from January 1997 to August 2002 were included in the present study. This study was approved by the institutional review board of Chonbuk National University Hospital. Informed consent was provided according to the Declaration of Helsinki.

The mean age at diagnosis of the 145 patients was 46.04 years (range: 22-72 years). Eighty-eight patients received modified radical mastectomy, and fifty-seven patients received breast conserving surgery. One hundred and twenty-nine patients received systemic adjuvant chemotherapy [CMF (cyclophosphamide, methotrexate and fluorouracil 5FU) chemotherapy or anthracyclineand taxane-based chemotherapy] and 121 patients received adjuvant endocrine therapy. One hundred and ten patients received both chemotherapy and endocrine therapy, and 5 patients received no adjuvant therapy. The median followup duration was 144.9 months (range, 7.7 - 192.6). Among the 145 BRCA patients, 21 patients experienced local relapse, 33 patients had latent distant metastasis, and 44 patients died from BRCA at the follow-up endpoint. The median survival was 192.0 months and the five- and tenyear survival rates for the entire BRCA patients were $81 \%$ and $74 \%$, respectively. All the cases were reviewed and classified by two pathologists (KY Jang and SJ Noh) according to the World Health Organization Classification [24], and pathologic staging as reviewed in the 7 th edition of the American Joint Committee on Cancer staging system [25]. The histologic diagnoses of 145 cases of BRCA were 137 invasive ductal carcinomas and 8 invasive lobular carcinomas. The patients were grouped according to the age, TNM stage, histologic type, modified Bloom and Richardson histologic grade (tubule and gland formation, nuclear pleomorphism and mitotic counts) [24], presence of local relapse, distant metastasis, and immunohistochemical expression of human epidermal growth factor receptor 2 (HER2), ER and PR.

\section{Immunohistochemical staining and scoring}

Immunohistochemical staining was performed using $3.0 \mathrm{~mm}$ tumor cores for tissue microarray (TMA). To establish the TMA, we reviewed all of the H\&E slides and took two $3.0 \mathrm{~mm}$ tissue cores from the paraffin-embedded tissue blocks per case at the area of highest tumor grade. An antigen retrieval procedure was performed with sodium citrate buffer using a microwave oven for 20 minutes. The following markers were used: NGF (1:200, Abcam, Cambridge, UK) and HO1 (1:200, Enzo Life Sciences, PA, USA). Immunohistochemical staining for NGF and HO1 were evaluated by the sum of the staining intensity scores and the staining area scores in each TMA core [26,27]. The staining intensity was scored as 0 (no staining), 1 (weak staining), 2 (intermediate staining), and 3 (strong staining). The staining area was scored as 0 (no staining cells), 1 ( $1 \%$ of the cells stained positive), 2 (2-10\% of the cells stained positive), 3 (11-33\% of the cells stained positive), 4 (34-66\% of the cells stained positive), and 5 (66-100\% of the cells stained positive). Thereafter, the combined score (obtained by adding the sum of the scores of two different TMA cores) was used for further analysis. The maximum combined score was 16 and the minimum sum score was zero. Subsequently, the expression of NGF and $\mathrm{HO} 1$ were grouped as positive or negative by receiver operating characteristic curve analysis at the highest 
positive likelihood ratio point for the death of BRCA patients. The cut-off point for NGF expression was 9 and was 14 for $\mathrm{HO} 1$ expression. The expression of NGF was considered positive when a combined score was greater or equal to nine and $\mathrm{HO} 1$ expression was considered positive when a combined score was greater than or equal to fourteen. HER2 immunostaining was considered positive if $30 \%$ or more of the tumor cell showed strong complete membrane staining. Immunostaining for estrogen receptor (ER) and progesterone receptor (PR) were considered positive if $1 \%$ or more of the tumor cells showed nuclear staining. Immunohistochemical scoring was performed by two pathologists (KY Jang and SJ Noh) who were blinded to the clinicopathologic information of the patients.

\section{Statistical analysis}

The relationships between NGF and HO1 expression and other clinicopathological factors were determined using the Pearson's chi-square test. The primary point of interest was overall survival (OS) and relapse-free survival (RFS). The follow-up endpoint was the date of death or the date of last contact through December 2012. OS duration was measured as the time from diagnosis to date of death from BRCA and the patients who were alive at last contact or died from other causes were treated as censored. RFS was calculated as the time from diagnosis to the date of relapse, death from BRCA, or last contact. Patients who were alive at last contact or died from other causes and who did not experience the relapse were treated as censored for RFS analysis. Univariate and multivariate Cox regression hazard analysis were performed to estimate the impact of clinicopathologic factors and expression of each marker on OS and RFS. Kaplan-Meier survival analysis with a log-rank test was used to illustrate the cumulative survival curve for OS and RFS. Statistical analyses were calculated using SPSS statistical software (IBM, version 18.0, CA, USA). $P$-values less than 0.05 were considered to be statistically significant.

\section{Results}

\section{NGF and HO1 expression and its correlations with}

\section{clinicopathologic factors of BRCA patients}

The expression of NGF and HO1 was seen mainly in the cytoplasm of tumor cells, and the expression of NGF and HO1 was grouped positive in $31 \%$ (45/145 of cases) and $49 \%(71 / 145)$ of BRCA samples, respectively (Figure 1). The expression of NGF was significantly associated with age $(P=0.035)$, histologic grade $(P=0.020)$, presence of latent distant metastasis $(P=0.004)$, and the expression of HER2 $(P=0.002)$ and ER $(P=0.005)$. Especially, a strong positive correlation between NGF and HO1 was found $(P<0.001)$. The expression of HO1 was significantly correlated with age $(P=0.029)$, histologic grade
$(P=0.017)$, presence of latent distant metastasis $(P<0.001)$, and HER2 expression $(P<0.001)$ (Table 1$)$.

\section{Expression of NGF and $\mathrm{HO} 1$ correlates with overall survival and relapse-free survival in BRCA according to univariate analysis}

Univariate survival analyses of the expression of NGF and HO1 and clinicopathological factors for OS and RFS are listed in Table 2. In the 145 BRCA patients, age of the patients (Log-rank, OS; $P<0.001$, RFS; $P=0.017$ ), HER2 expression (Log-rank, OS; $P<0.001$, RFS; $P<0.001$ ), NGF expression (Log-rank, OS; $P<0.001$, RFS; $P<0.001$ ), and HO1 expression (Log-rank, OS; $P<0.001$, RFS; $P<0.001$ ) were significantly associated with shorter OS and RFS (Figure 2A). The patients with NGF expression had a 4.674-fold (95\% CI, 2.541-8.598) greater risk of death $(P<0.001)$ and its expression significantly associated with shorter RFS $(P<0.001, \mathrm{HR} ; 3.550,95 \% \mathrm{CI} ; 2.074-6.076)$. The expression of $\mathrm{HO} 1$ predicted shorter OS $(P<0.001$, HR; 6.101, 95\% CI; 2.832-13.143) and RFS $(P<0.001$, HR; 3.476, 95\% CI; 1.914-6.314). TNM stage was significantly associated with shorter OS (Log-rank, $P=0.010$ ).

We also performed additional survival analysis in the patients which received adjuvant chemotherapy or endocrine therapy. Among the patients who received systemic adjuvant chemotherapy, HER2 expression (Log-rank, OS; $P<0.001$, RFS; $P<0.001$ ), NGF expression (Log-rank, OS; $P<0.001$, RFS; $P<0.001)$, and HO1 expression (Log-rank, OS; $P<0.001$, RFS; $P<0.001$ ) were significantly associated with shorter OS and RFS (Figure 2B). The age of the patients $(P=0.001)$ and TNM stage $(P=0.003)$ were significantly associated with shorter OS. Among the patients who received systemic adjuvant endocrine therapy, the age of the patients (Log-rank, OS; $P<0.001$, RFS; $P=0.022$ ), the expression of HER2 (Log-rank, OS; $P=0.007$, RFS; $P=0.005$ ), NGF (Log-rank, OS; $P<0.001$, RFS; $P<0.001$ ), and HO1 (Log-rank, OS; $P<0.001$, RFS; $P<0.001)$ were significantly associated with both OS and RFS (Figure 2C). TNM stage was significantly associated with shorter OS (Log-rank, $P=0.024$ ).

Thereafter, to investigate the prognostic effect of the combined expression pattern of NGF and HO1 (NGF/ HO1 expression), we analyzed the prognostic effect of the expression of one marker in two separate groups according to the positivity of another marker. In the $\mathrm{NGF}^{-}$ group, the expression of $\mathrm{HO} 1$ significantly associated OS (Log-rank, $P<0.001$ ) and RFS (Log-rank, $P=0.004$ ) (Figure 3A). However, HO1 expression did not affect for the survival of patients in $\mathrm{NGF}^{+}$group (Log-rank, OS; $P=0.514$, RFS; $P=0.831$ ) (Figure 3B). However, NGF expression significantly associated with shorter OS of BRCA patients in both $\mathrm{HO}^{-}$group (Log-rank, OS; $P=$ 0.011, RFS; $P<0.001$ ) and $\mathrm{HO}^{+}$(Log-rank, OS; $P=$ 0.045 , RFS; $P=0.071$ ) group (Figure $3 \mathrm{C}$ and $3 \mathrm{D}$ ). Based 


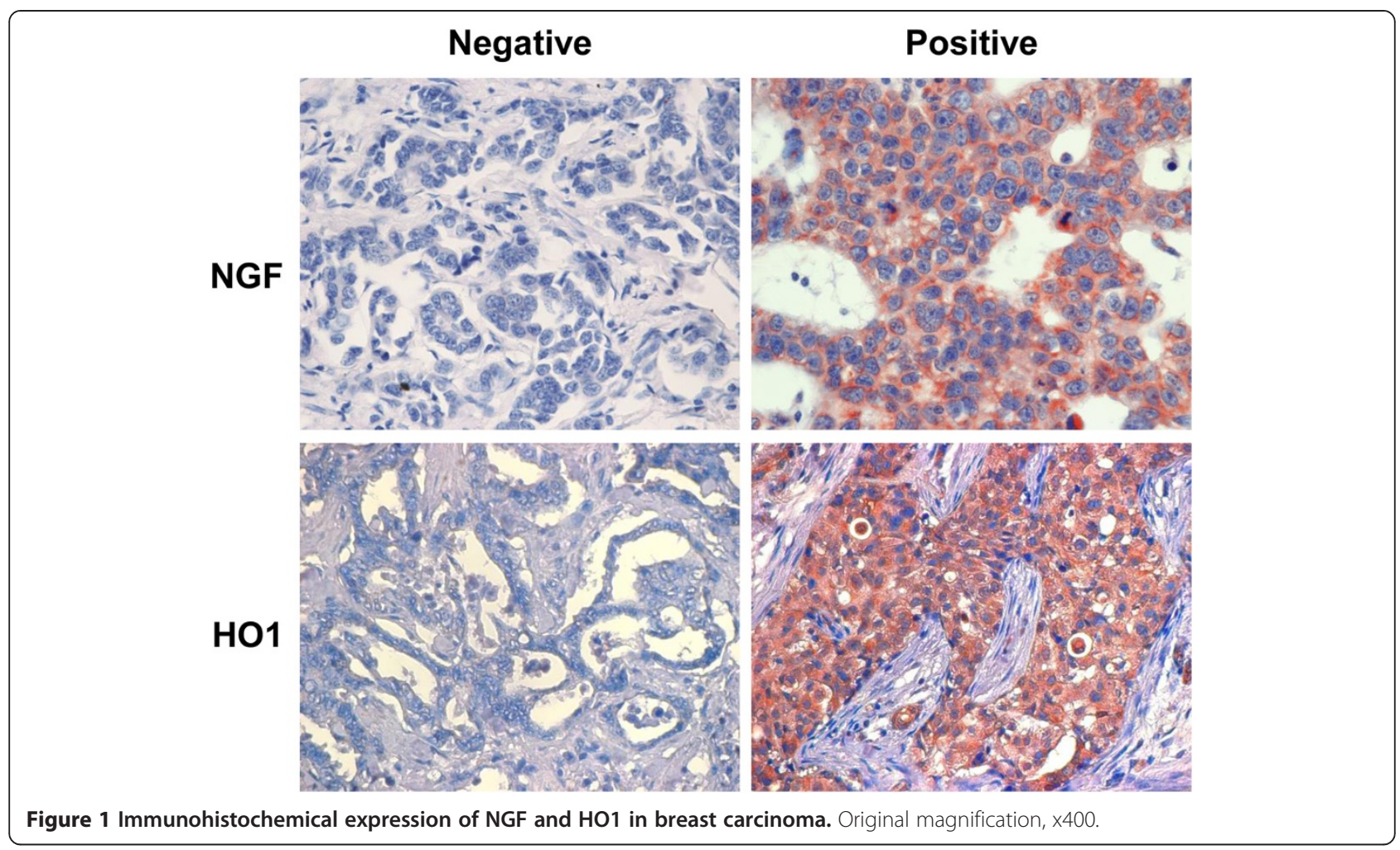

on these results, we divided the BRCA patients into three groups according to the NGF/HO1 expression pattern as shown in Figure 4. The NGF/HO1 expression was significantly associated with shorter OS (Log-rank, $P<0.001$ ) and RFS (Log-rank, $P<0.001$ ) (Figure $4 \mathrm{~A})$. The $\mathrm{NGF}^{-} / \mathrm{HO}^{-}$group showed favorable prognosis and the $\mathrm{NGF}^{+}$/anyHO1 group showed the poorest prognosis. The ten-year survival rate of the $\mathrm{NGF}^{-} / \mathrm{HO}^{-}$ group, the $\mathrm{NGF}^{-} / \mathrm{HO}^{+}$group, and the $\mathrm{NGF}^{+} / \mathrm{anyHO} 1$ groups were $94 \%, 71 \%$, and $47 \%$, respectively (Figure $4 \mathrm{~B}$ ).

\section{NGF expression, HO1 expression, and NGF/HO1 expression is the independent, unfavorable prognostic predictor for overall survival in BRCA}

The variables significantly associated with OS and RFS by univariate analysis were considered in the multivariate analysis. The variables considered in the multivariate analysis were age, TNM stage, histologic grade, and the expression of HER2, NGF, and HO1. Among the 145 BRCA patients, NGF expression was independent predictors of shorter OS and RFS. The patients with tumors expressing NGF had a 2.174-fold (95\% CI; 1.073-4.404, $P=0.031$ ) greater risk of shorter OS and a 3.042-fold (95\% CI; 1.746-5.299, $P<0.001$ ) greater risk of shorter RFS. The expression of HO1 $(P<0.001, \mathrm{HR}$; 4.847, 95\% CI; 1.990-11.807) and TNM stage (overall $P=0.002$ ) were also independent prognostic indicators of OS. The expression of HER2 was an independent prognostic predictor of RFS ( $P=0.017$, HR; $1.980,95 \% \mathrm{CI}$; 1.132 3.464).To test the impact of the NGF/HO1 expression pattern on OS and RFS of BRCA patients, multivariate analysis was performed with the inclusion of NGF/HO1 expression instead of the individual expression of NGF and HO1. NGF/HO1 expression was also significantly associated with OS (overall $P<0.001$ ) and RFS (overall $P<0.001$ ) (Table 3).

Among patients who received chemotherapy, TNM stage (overall $P<0.001)$, HO1 expression $(P<0.001)$, and NGF/HO1 expression (overall $P<0.001$ ) were the independent prognostic predictor of OS. The expression of HER2 $(P=0.024)$ and NGF $(P<0.001)$, and NGF/HO1 expression (overall $P<0.001$ ) were the independent prognostic indicators of RFS for BRCA patients. Among patients who received endocrine therapy, the age of the patients $(P=0.007)$, TNM stage $(P=0.022)$, HO1 expression $(P<0.001)$, and NGF/HO1 expression (overall $P<$ 0.001 ) were independent prognostic indicators of OS for BRCA patients. The expression of HER2 $(P=0.029)$ and NGF $(P<0.001)$, and NGF/HO1 expression (overall $P<$ 0.001 ) were independent prognostic indicators of RFS for BRCA patients.

\section{Discussion}

In this study, we have investigated the immunohistochemical expression of NGF and HO1 in BRCA patients and demonstrated that the expression of NGF and HO1 
Table 1 Association of the expression of NGF and HO1 with clinicopathological factors

\begin{tabular}{|c|c|c|c|c|c|c|}
\hline \multirow[t]{2}{*}{ Characteristics } & & \multirow[t]{2}{*}{ No. } & \multirow{2}{*}{$\begin{array}{c}\text { NGF } \\
\text { Positive }\end{array}$} & \multicolumn{3}{|c|}{ HO1 } \\
\hline & & & & $P$ & Positive & $P$ \\
\hline \multirow[t]{2}{*}{ Age, y } & $<50$ & 104 & $27(26 \%)$ & 0.035 & $45(43 \%)$ & 0.029 \\
\hline & $\geq 50$ & 41 & $18(44 \%)$ & & $26(63 \%)$ & \\
\hline \multirow[t]{3}{*}{ TNM stage } & । & 29 & $9(31 \%)$ & 0.836 & 17 (59\%) & 0.507 \\
\hline & $\|$ & 97 & $28(29 \%)$ & & 45 (46\%) & \\
\hline & III and IV & 19 & $7(37 \%)$ & & $9(47 \%)$ & \\
\hline \multirow[t]{3}{*}{ T stage } & 1 & 41 & $10(24 \%)$ & 0.424 & $22(54 \%)$ & 0.675 \\
\hline & 2 & 95 & $31(33 \%)$ & & $44(46 \%)$ & \\
\hline & 3 and 4 & 9 & $4(44 \%)$ & & $5(56 \%)$ & \\
\hline \multirow[t]{2}{*}{ LN metastasis } & Absence & 83 & $26(31 \%)$ & 0.930 & 39 (47\%) & 0.582 \\
\hline & Presence & 62 & $19(31 \%)$ & & $32(52 \%)$ & \\
\hline \multirow[t]{2}{*}{ Latent distant metastasis } & Absence & 112 & $28(25 \%)$ & 0.004 & 45 (40\%) & $<0.001$ \\
\hline & Presence & 33 & $17(52 \%)$ & & $26(79 \%)$ & \\
\hline \multirow[t]{2}{*}{ Histologic type } & Ductal & 137 & $43(31 \%)$ & 0.704 & 67 (49\%) & 0.952 \\
\hline & Lobular & 8 & $2(25 \%)$ & & $4(50 \%)$ & \\
\hline \multirow[t]{3}{*}{ Histologic grade } & 1 & 49 & $9(18 \%)$ & 0.020 & 20 (41\%) & 0.017 \\
\hline & 2 & 67 & 22 (33\%) & & 30 (45\%) & \\
\hline & 3 & 29 & 14 (48\%) & & 21 (72\%) & \\
\hline \multirow[t]{2}{*}{ HER2 } & Negative & 105 & 25 (24\%) & 0.002 & 42 (40\%) & $<0.001$ \\
\hline & Positive & 40 & 20 (50\%) & & 29 (73\%) & \\
\hline \multirow[t]{2}{*}{ ER } & Negative & 65 & 28 (43\%) & 0.005 & 35 (54\%) & 0.289 \\
\hline & Positive & 80 & 17 (21\%) & & 36 (45\%) & \\
\hline \multirow[t]{2}{*}{ PR } & Negative & 60 & $23(38 \%)$ & 0.110 & 34 (57\%) & 0.119 \\
\hline & Positive & 85 & 22 (26\%) & & 37 (44\%) & \\
\hline \multirow[t]{2}{*}{$\mathrm{HO} 1$} & Negative & 74 & $5(7 \%)$ & $<0.001$ & & \\
\hline & Positive & 71 & $40(56 \%)$ & & & \\
\hline
\end{tabular}

Table 2 Univariate Cox proportional hazards regression analysis for overall survival and relapse-free survival

\begin{tabular}{|c|c|c|c|c|c|c|c|}
\hline \multirow[t]{2}{*}{ Characteristics } & \multirow[t]{2}{*}{ No. } & \multirow{2}{*}{$\begin{array}{l}\text { OS } \\
\text { HR }\end{array}$} & \multicolumn{5}{|c|}{ RFS } \\
\hline & & & $95 \% \mathrm{Cl}$ & $P$ & HR & $95 \% \mathrm{Cl}$ & $P$ \\
\hline Age, $y, \geq 50$ (vs. < 50) & $41 / 145$ & 2.928 & $1.620-5.293$ & $<0.001$ & 1.914 & $1.112-3.295$ & 0.019 \\
\hline TNM stage, I & $29 / 145$ & 1 & & 0.016 & 1 & & 0.197 \\
\hline$\|$ & $97 / 145$ & 2.482 & $0.874-7.046$ & 0.088 & 1.386 & $0.644-2.983$ & 0.403 \\
\hline III and IV & $19 / 145$ & 5.154 & $1.614-16.457$ & 0.006 & 2.288 & $0.902-5.799$ & 0.081 \\
\hline Histologic grade, 1 & $49 / 145$ & 1 & & 0.014 & 1 & & 0.087 \\
\hline 2 & $67 / 145$ & 1.218 & $0.575-2.579$ & 0.607 & 1.147 & $0.598-2.198$ & 0.680 \\
\hline 3 & $29 / 145$ & 2.818 & $1.293-6.139$ & 0.009 & 2.077 & $1.027-4.203$ & 0.042 \\
\hline HER2, positive (vs. negative) & $40 / 145$ & 2.765 & $1.525-5.012$ & $<0.001$ & 2.596 & $1.511-4.461$ & $<0.001$ \\
\hline ER, positive (vs. negative) & $80 / 145$ & 0.691 & $0.382-1.250$ & 0.222 & 0.911 & $0.533-1.557$ & 0.733 \\
\hline NGF, positive (vs. negative) & $45 / 145$ & 4.674 & $2.541-8.598$ & $<0.001$ & 3.55 & $2.074-6.076$ & $<0.001$ \\
\hline HO1, positive (vs. negative) & $71 / 145$ & 6.101 & $2.832-13.143$ & $<0.001$ & 3.476 & $1.914-6.314$ & $<0.001$ \\
\hline $\mathrm{NGF} / \mathrm{HO} 1, \mathrm{NGF}^{-} / \mathrm{HO}^{-}$ & $69 / 145$ & 1 & & $<0.001$ & 1 & & $<0.001$ \\
\hline $\mathrm{NGF}^{-} / \mathrm{HO}^{+}$ & $31 / 145$ & 5.019 & $1.855-13.578$ & 0.001 & 2.935 & $1.338-6.436$ & 0.007 \\
\hline $\mathrm{NGF}^{+} / \mathrm{anyHO} 1$ & $45 / 145$ & 9.717 & $4.003-23.586$ & $<0.001$ & 5.41 & $2.754-10.625$ & $<0.001$ \\
\hline
\end{tabular}




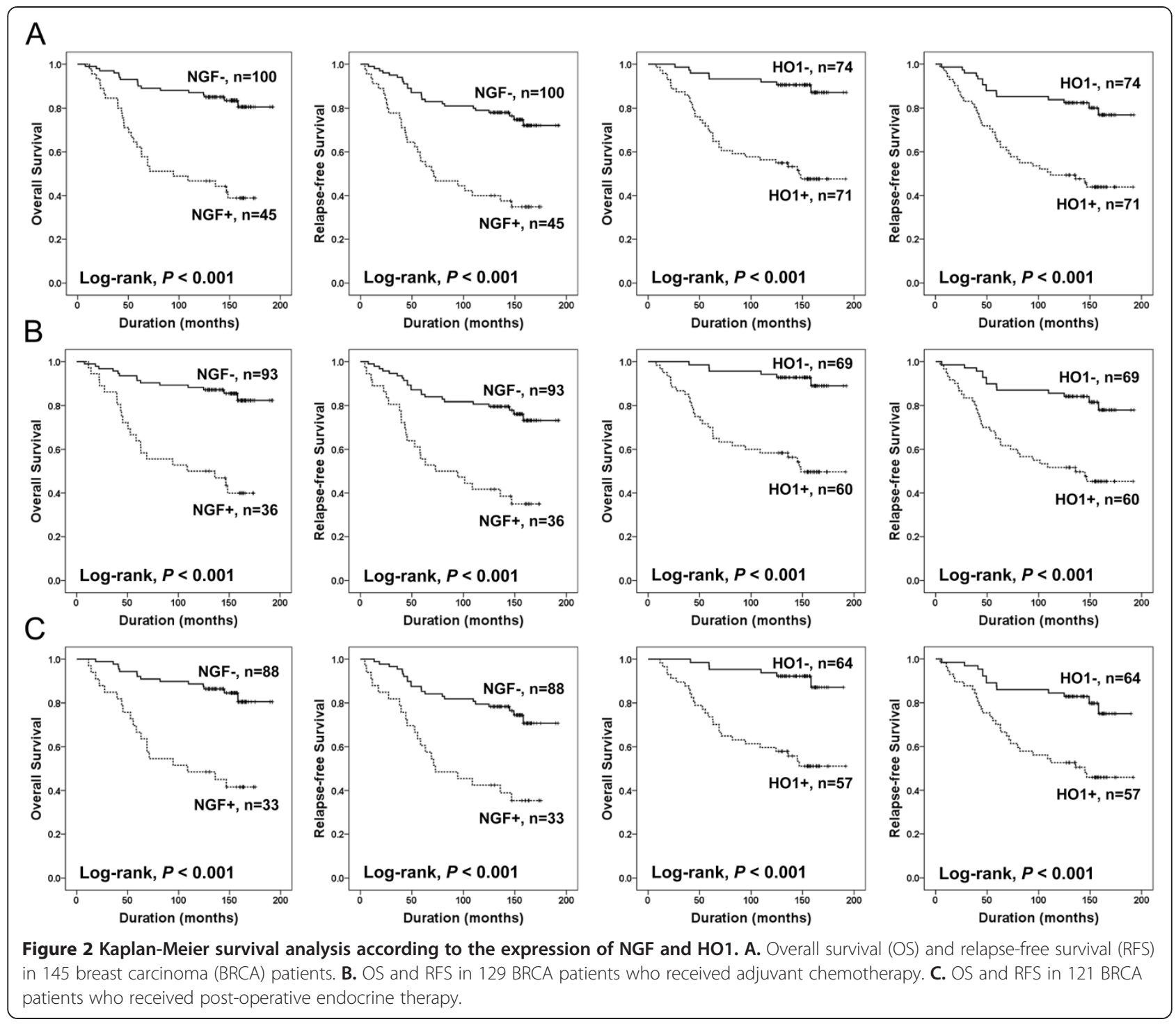

were significantly associated with each other, and both have a significant association with HER2 expression, histologic grade, and latent distant metastasis. Moreover, the expression of NGF and HO1 was associated with shorter OS and RFS of BRCA by univariate analysis and multivariate analysis revealed the expression of NGF and $\mathrm{HO} 1$ as an independent prognostic indicator of OS for BRCA patients. Interestingly, the NGF/HO1 expression pattern was also a significant prognostic indicator of OS and RFS of BRCA patients by univariate and multivariate analysis. Especially, the patients with tumors expressing $\mathrm{NGF}$ had the shortest survival and the $\mathrm{NGF}^{-} / \mathrm{HO}^{-}$ phenotype associated with favorable prognosis. This result suggests that both NGF and HO1 could be prognostic indicators and potential therapeutic targets for BRCA patients.

NGF is a neurotrophin, which controls development and survival of neuronal cells. In addition to its neurotrophic effect, NGF has been reported to be up-regulated in several malignant tumors $[1,28]$. Interestingly, NGF is not detected in normal breast epithelial cells and is not mitogenic for normal breast epithelial cells. In contrast, NGF is expressed in BRCA cells and stimulates growth of BRCA cells via an autocrine loop [7,29]. NGF stimulates proliferation and inhibits apoptosis of BRCA cells [2]. The pro-proliferative role of NGF in BRCA is mediated by activation of TrkA, $\mathrm{p} 75^{\mathrm{NTR}}$, and NFkB pathways $[2,8]$. Furthermore, NGF is involved in BRCA angiogenesis [3]. NGF increases the levels of secreted vascular endothelial growth factor in both human umbilical vein endothelial cells and BRCA cell lines [3]. Moreover, the precursor of NGF was overproduced in BRCA compared with benign breast tissue and involved in the stimulation of the invasion of BRCA cells [30]. TrkA overexpression promotes growth, migration, invasion, and survival of a BRCA cell line, enhances angiogenesis, and promotes metastasis of BRCA cells in mice [5]. Blocking of 

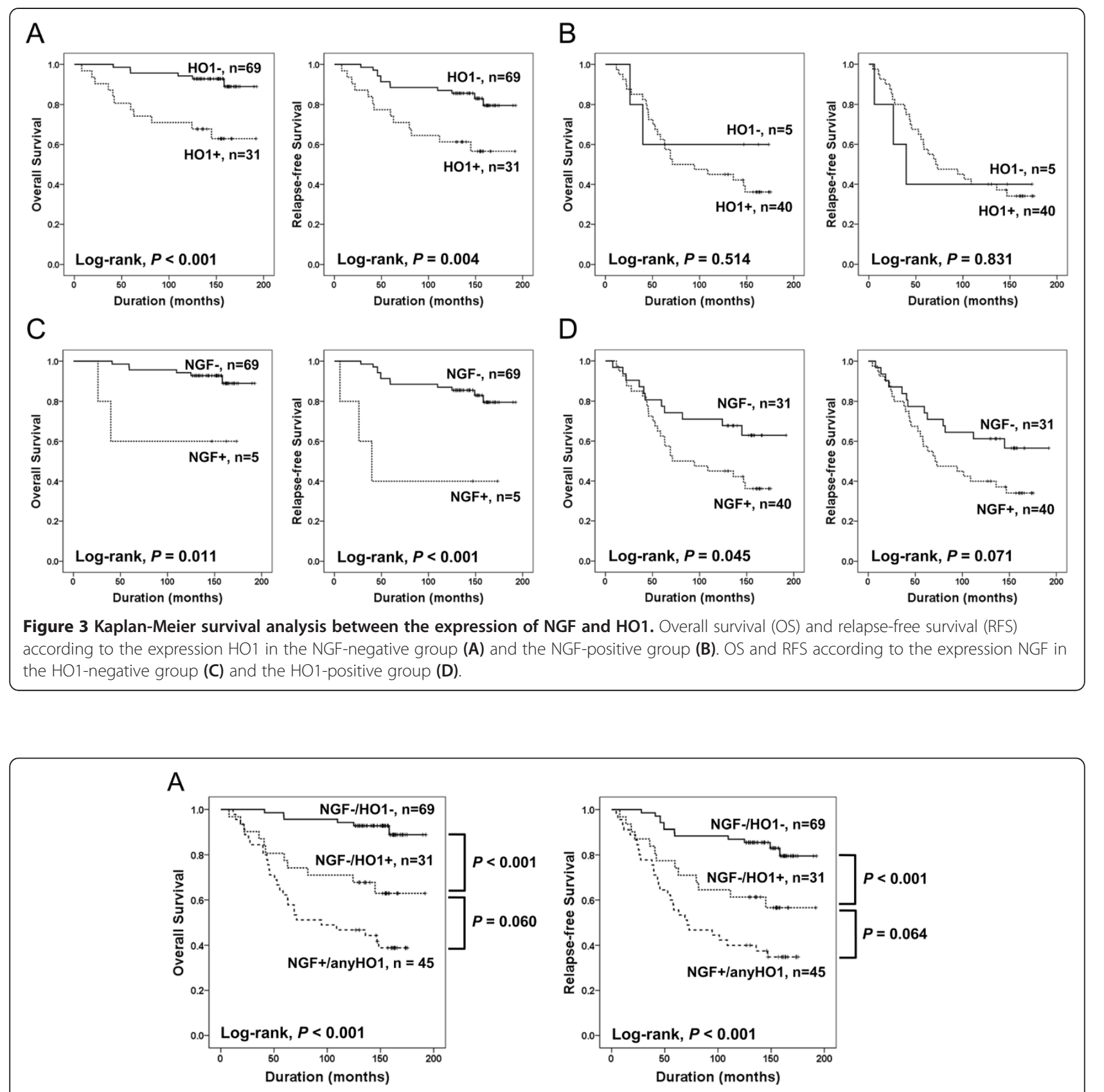

B

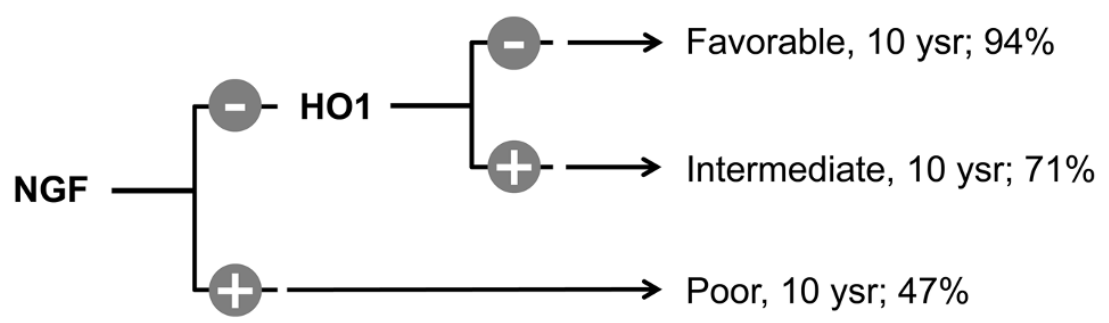

Figure 4 Prognostic significance of the combined expression pattern of NGF and HO1. A. Kaplan-Meier survival analysis for overall survival and relapse-free survival between the $\mathrm{NGF}^{-} / \mathrm{HO}^{-}$, the $\mathrm{NGF}^{-} / \mathrm{HO}^{+}$, and the $\mathrm{NGF}^{+} /$any $\mathrm{HO} 1$ subgroups of breast carcinoma patients. B. An algorithm for the sub-grouping of breast carcinoma patients into three sub-groups according to the expression patterns of NGF and HO1. 10 ysr; ten-year survival rate. 
Table 3 Multivariate Cox proportional hazards regression analysis for overall survival and relapse-free survival

\begin{tabular}{|c|c|c|c|c|c|c|}
\hline \multirow[t]{2}{*}{ Characteristics } & \multirow{2}{*}{$\begin{array}{l}\text { OS } \\
\text { HR }\end{array}$} & \multicolumn{5}{|c|}{ RFS } \\
\hline & & $95 \% \mathrm{Cl}$ & $P$ & HR & $95 \% \mathrm{Cl}$ & $P$ \\
\hline TNM stage, I & 1 & & 0.002 & & & \\
\hline$\|$ & 3.542 & $1.241-10.109$ & 0.018 & & & \\
\hline III and IV & 7.933 & $2.441-25.787$ & $<0.001$ & & & \\
\hline HER2, ${ }^{*}$ positive (vs. negative) & & & & 1.98 & $1.132-3.464$ & 0.017 \\
\hline NGF, positive (vs. negative) & 2.174 & $1.073-4.404$ & 0.031 & 3.042 & $1.746-5.299$ & $<0.001$ \\
\hline HO1, ${ }^{*}$ positive (vs. negative) & 4.847 & $1.990-11.807$ & $<0.001$ & & & \\
\hline $\mathrm{NGF} / \mathrm{HOl}^{* *}{ }^{*} \mathrm{NGF}^{-} / \mathrm{HOl}^{-}$ & 1 & & $<0.001$ & 1 & & $<0.001$ \\
\hline $\mathrm{NGF}^{-} / \mathrm{HO}^{+}$ & 6.542 & $2.381-17.979$ & $<0.001$ & 3.5 & $1.574-7.778$ & 0.002 \\
\hline $\mathrm{NGF}^{+} / \mathrm{anyHO} 1$ & 11.206 & $4.595-27.330$ & $<0.001$ & 6.011 & $3.039-11.888$ & $<0.001$ \\
\hline
\end{tabular}

* The variables included in the multivariate analysis were age, TNM stage, and the expression of HER2, NGF, and HO1. ** The variables included in the multivariate analysis were age, TNM stage, HER2 expression, and the combined expression pattern of NGF and HO1 (NGF/HO1).

NGF with anti-NGF antibodies or small interfering RNA against NGF inhibited tumor growth and metastasis [6] and inhibitors for TrkA or $\mathrm{p} 75^{\mathrm{NTR}}$, downstream signaling targets of NGF, also had pro-apoptotic and anti-proliferative effects on BRCA cells [8]. The inhibition of the precursor of NGF by small interfering RNA inhibited invasion activity of BRCA cells [30]. Therefore, NGF has been suggested as a potential therapeutic target for the treatment of malignant tumors, especially in BRCA $[6,8]$. In our study, high NGF expression was associated with high histologic grade and the presence of distant metastasis, and predicted poorer survival of BRCA patients. The poor prognosis of the patients with NGF-expressing tumor might be related with the ability of NGF-TrkA signaling to induce chemoresistance [31]. Therefore, there is a possibility that NGF-targeted therapy with a combination of conventional chemotherapy could be helpful for BRCA patients. In agreement with our findings, the expression of the NGFRs TrkA and $\mathrm{p} 75^{\mathrm{NTR}}$ was associated with poor prognosis of pancreatic cancer patients [4]. In addition, similar results found in a recent report which demonstrated that the expression of NGFR significantly associated with the higher histologic grade of BRCA, suggesting the expression of NGFR as a potential indicator of poor prognosis [32]. In this large cohort study in BRCA, the expression of NGFR was negatively correlated with the expression of ER and indicative for the basal-like BRCA or luminal B subtypes [32]. Our result has shown a negative correlation between NGF expression and ER expression.

Despite recent advances in diagnosis and treatment modalities, BRCA remains the second leading cause of cancer-related death among women [33]. Recently developed targeted therapies, especially for the HER2, have led to the improvement of overall outcomes of BRCA patients [34-36]. Therefore, investigation of HER2 expression is crucial for the treatment of BRCA patients. However, the number of BRCA patients who benefit from targeted therapy is limited. The amplification of the HER2 gene and overexpression of the HER2 protein has been detected in about $25 \%$ of BRCA and most patients with advanced BRCA with HER2 gene amplification developed resistance to treatment $[34,35]$. However, the resistance mechanism to anti-HER2 treatments remains largely unexplained, and a new therapeutic approach for BRCA is needed. In our study, NGF expression was significantly correlated with HER2-positive status and the positivity of both NGF and HER2 predicted poor survival of BRCA patients. Similarly, a cooperative role of HER2 and NGF in the progression of BRCA has been previously reported [37], and NGF was suggested as a potential therapeutic target of BRCA [6]. However, when we separately analyzed the prognostic impact of NGF expression according to the expression status of HER2, NGF expression predicted poor survival of BRCA patients regardless of the positivity of HER2. NGF expression predicted poor OS in both the HER2-negative (Log-rank, $P=0.011$ ) and HER2-positive subpopulations (Log-rank, $P=0.005$ ). These results suggest the possibility that NGF has mechanism involved in the progression of BRCA which are independent of HER2-related mechanisms. Therefore, NGF-targeted therapy may be beneficial for BRCA patients in addition to the HER2-based conventional therapy.

In the NGF-TrkA signaling pathway, NGF is also known as an inducer of $\mathrm{HO} 1$ [22,23]. NGF increases HO1 expression through the receptor tyrosine phosphorylation pathway, and then $\mathrm{HO} 1$ causes the anti-apoptotic effect of NGF [22]. In neurodegenerative disease models, NGF protects cells against oxidative stress by inducing $\mathrm{HO} 1$ expression in a phosphatidylinositol 3-kinase-dependent manner [23]. These results suggest that there is a cooperative role between NGF and HO1 in cellular adaptation to stress and induction of resistance to death. When considering the tumor-progressing role of NGF, there is a possibility that $\mathrm{HO} 1$ is also involved in the progression of cancers. Our study has also showed a significant correlation between the expression of $\mathrm{HO} 1$ and NGF. 89\% (40/45) of NGF-expressing BRCA co-expressed HO1. 
These results suggest the possibility that NGF and HO1 mediated pathways are involved in the progression of BRCA. However, interestingly, $\mathrm{HO} 1$ expression associated with shorter OS and RFS in the NGF-negative group, but not in the NGF-positive group. This finding suggests the possibility that $\mathrm{HO} 1$ may have its own role in the progression of BRCA-independent of an NGF- related mechanism.

The expression of HO1 is increased in various cancer cells compared with normal cells $[17,18,38,39]$, which is associated with unfavorable prognosis of cancer patients [18]. The tumor-progressive role of $\mathrm{HO} 1$ is related to its roles in the inhibition of apoptosis [22], promotion of tumor angiogenesis [40,41], and chemoresistance [14]. $\mathrm{HO} 1$ also augments cancer cell migration and invasion by inducing MMP-9, CD147, and EGFR [18]. In the present study, the expression of $\mathrm{HO} 1$ was associated with unfavorable factors, distant metastatic relapse, higher histologic grade, and positive HER2 expression, and predicted shorter OS for BRCA patients. However, in contrast to our findings, there are conflicting reports that $\mathrm{HO} 1$ inhibits the proliferation and invasiveness of cancer cells [42-44], and that the expression of HO1 predicted favorable OS of colon cancer patients [20]. These conflicting findings may be related to the diverse roles of $\mathrm{HO} 1$ in various conditions or the status of the cells during tumorigenesis. HO1 may be protective for healthy cells in tumorinducing injury; however, it could be tumor progressive in already developed tumors [45]. Therefore, further study is needed to explore the exact role(s) of $\mathrm{HO} 1$ and its possible correlation with NGF in BRCA tumorigenesis.

Another interesting finding of this study is that the combined expression pattern of NGF and HO1 is helpful for the prediction of the prognosis of BRCA patients. The patients with tumors expressing NGF had the shortest OS and RFS; furthermore, the patients with tumor which did not express NGF or HO1 showed the longest survival time. Multivariate analysis revealed NGF/HO1 expression as an independent prognostic indicator of OS and RFS. Therefore, this result suggests that the combined expression pattern of NGF and HO1 might be usable as a prognostic indicator for BRCA patients.

\section{Conclusions}

In summary, the results of this study have shown that the expression of NGF and HO1 were significantly associated with each other and that the expression of both of them significantly correlated with unfavorable clinicopathological factors and predicted shorter survival of BRCA patients. Therefore, these results suggest the possibility that the NGF-HO1 pathway may be involved in breast carcinogenesis and progression. In addition, an algorithm for the sub-grouping of breast carcinoma patients into three sub-groups according to the expression patterns of NGF and $\mathrm{HO} 1$ also predicted survival of
BRCA patients. Therefore, this result suggests the possibility that individual expression of NGF or HO1, and the combined expression pattern of NGF and HO1 could be the new prognostic indicator of BRCA patients.

\section{Abbreviations}

BRCA: Breast carcinoma; Cl: Confidence interval; ER: Estrogen receptor HER2: Human epithelial growth factor receptor 2; HO1: Heme oxygenase-1; HR: Hazard ratio; LN: Lymph node; NGF: Nerve growth factor; NGFR: Nerve growth factor receptor; OS: Overall survival; PR: Progesterone receptor; RFS: Relapse-free survival; TMA: Tissue microarray; TrkA: Tropomyosin-related kinase $A$.

\section{Competing interests}

The authors declare that they have no competing interests.

\section{Authors' contributions}

SJN, JSB, SHJ, BHP, HL, MJC, WSM, MJK and KYJ participated in the study design. JSB and UJ did the immunohistochemical staining. SJN, UJ, HSP, KSK, SHJ, HJY, MJC, MJK and KYJ were involved in data collection and data interpretation. SJN, KSK and KYJ participated in the statistical analyses. SJN, HSP, KSK, HJY, HL, BHP, WSM and KYJ wrote the manuscript. All authors read and approved the final manuscript.

\section{Acknowledgements}

This work was supported by the National Research Foundation of Korea (NRF) grant funded by the Korea government (MSIP) (No. 2008-0062279). We thank DB Leveson-Gower who provided medical writing services.

\section{Author details}

${ }^{1}$ Departments of Pathology, Research Institute of Clinical Medicine and Research Institute for Endocrine Sciences, Chonbuk National University Medical School, Jeonju, Republic of Korea. ${ }^{2}$ Departments of Preventive Medicine, Chonbuk National University Medical School, Jeonju, Republic of Korea. ${ }^{3}$ Departments of Surgery, Chonbuk National University Medical School, Jeonju, Republic of Korea. ${ }^{4}$ Departments of Forensic Medicine, Chonbuk National University Medical School, Jeonju, Republic of Korea. ${ }^{5}$ Departments of Biochemistry, Chonbuk National University Medical School, Research Institute for Endocrine Sciences, Jeonju, Republic of Korea.

Received: 8 July 2013 Accepted: 29 October 2013

Published: 1 November 2013

\section{References}

1. Kruttgen A, Schneider I, Weis J: The dark side of the NGF family: neurotrophins in neoplasias. Brain Pathol 2006, 16:304-310.

2. Descamps S, Toillon RA, Adriaenssens E, Pawlowski V, Cool SM, Nurcombe V Le Bourhis X, Boilly B, Peyrat JP, Hondermarck H: Nerve growth factor stimulates proliferation and survival of human breast cancer cells through two distinct signaling pathways. J Biol Chem 2001, 276:17864-17870.

3. Romon R, Adriaenssens E, Lagadec C, Germain E, Hondermarck H, Le Bourhis $X$ : Nerve growth factor promotes breast cancer angiogenesis by activating multiple pathways. Mol Cancer 2010, 9:157.

4. Dang C, Zhang Y, Ma Q, Shimahara Y: Expression of nerve growth factor receptors is correlated with progression and prognosis of human pancreatic cancer. J Gastroenterol Hepatol 2006, 21:850-858.

5. Lagadec C, Meignan S, Adriaenssens E, Foveau B, Vanhecke E, Romon R, Toillon RA, Oxombre B, Hondermarck H, Le Bourhis X: TrkA overexpression enhances growth and metastasis of breast cancer cells. Oncogene 2009, 28:1960-1970.

6. Adriaenssens E, Vanhecke E, Saule P, Mougel A, Page A, Romon R, Nurcombe V, Le Bourhis $\mathrm{X}$, Hondermarck $\mathrm{H}$ : Nerve growth factor is a potential therapeutic target in breast cancer. Cancer research 2008, 68:346-351.

7. Dolle L, El Yazidi-Belkoura I, Adriaenssens E, Nurcombe V, Hondermarck H: Nerve growth factor overexpression and autocrine loop in breast cancer cells. Oncogene 2003, 22:5592-5601.

8. Naderi A, Hughes-Davies L: Nerve growth factor/nuclear factor-kappaB pathway as a therapeutic target in breast cancer. J Cancer Res Clin Oncol 2009, 135:211-216. 
9. Tenhunen R, Marver HS, Schmid R: The enzymatic conversion of heme to bilirubin by microsomal heme oxygenase. Proc Natl Acad Sci USA 1968, 61:748-755

10. Otterbein LE, Soares MP, Yamashita K, Bach FH: Heme oxygenase-1: unleashing the protective properties of heme. Trends Immunol 2003, 24:449-455.

11. Schulz S, Wong RJ, Jang KY, Kalish F, Chisholm KM, Zhao H, Vreman HJ, Sylvester KG, Stevenson DK: Heme oxygenase-1 deficiency promotes the development of necrotizing enterocolitis-like intestinal injury in a newborn mouse model. Am J Physiol Gastrointest Liver Physiol. in press.

12. Richards JA, Wigmore SJ, Devey LR: Heme oxygenase system in hepatic ischemia-reperfusion injury. World J Gastroenterol 2010, 16:6068-6078.

13. Banerjee P, Basu A, Wegiel B, Otterbein LE, Mizumura K, Gasser M, Waaga-Gasser AM, Choi AM, Pal S: Heme oxygenase-1 promotes survival of renal cancer cells through modulation of apoptosis- and autophagy-regulating molecules. J Biol Chem 2012, 287:32113-32123.

14. Kongpetch S, Kukongviriyapan V, Prawan A, Senggunprai L, Kukongviriyapan U, Buranrat B: Crucial role of heme oxygenase-1 on the sensitivity of cholangiocarcinoma cells to chemotherapeutic agents. PLOS One 2012, 7:e34994.

15. Liu ZM, Chen GG, Ng EK, Leung WK, Sung JJ, Chung SC: Upregulation of heme oxygenase- 1 and p21 confers resistance to apoptosis in human gastric cancer cells. Oncogene 2004, 23:503-513.

16. Maines MD, Abrahamsson PA: Expression of heme oxygenase-1 (HSP32) in human prostate: normal, hyperplastic, and tumor tissue distribution. Urology 1996, 47:727-733.

17. Gandini NA, Fermento ME, Salomon DG, Blasco J, Patel V, Gutkind JS, Molinolo AA, Facchinetti MM, Curino AC: Nuclear localization of heme oxygenase- 1 is associated with tumor progression of head and neck squamous cell carcinomas. Exp Mol Pathol 2012, 93:237-245.

18. Tsai JR, Wang HM, Liu PL, Chen YH, Yang MC, Chou SH, Cheng YJ, Yin WH, Hwang JJ, Chong IW: High expression of heme oxygenase-1 is associated with tumor invasiveness and poor clinical outcome in non-small cell lung cancer patients. Cell Oncol (Dordr) 2012, 35:461-471.

19. Degese MS, Mendizabal JE, Gandini NA, Gutkind JS, Molinolo A, Hewitt SM, Curino AC, Coso OA, Facchinetti MM: Expression of heme oxygenase-1 in non-small cell lung cancer (NSCLC) and its correlation with clinical data. Lung Cancer 2012, 77:168-175.

20. Becker JC, Fukui H, Imai Y, Sekikawa A, Kimura T, Yamagishi H, Yoshitake N, Pohle T, Domschke W, Fujimori T: Colonic expression of heme oxygenase1 is associated with a better long-term survival in patients with colorectal cancer. Scand J Gastroenterol 2007, 42:852-858.

21. Tsuji MH, Yanagawa T, Iwasa S, Tabuchi K, Onizawa K, Bannai S, Toyooka H, Yoshida H: Heme oxygenase-1 expression in oral squamous cell carcinoma as involved in lymph node metastasis. Cancer Lett 1999, 138:53-59.

22. Liu H, Nowak R, Chao W, Bloch KD: Nerve growth factor induces anti-apoptotic heme oxygenase- 1 in rat pheochromocytoma PC12 cells. J Neurochem 2003, 86:1553-1563.

23. Salinas M, Diaz R, Abraham NG, Ruiz de Galarreta CM, Cuadrado A: Nerve growth factor protects against 6-hydroxydopamine-induced oxidative stress by increasing expression of heme oxygenase- 1 in a phosphatidylinositol 3-kinase-dependent manner. J Biol Chem 2003, 278:13898-13904

24. Lakhani SR, Ellis IO, Schnitt SJ, Tan PH, Van de Vijver MJ: WHO Classification of Tumours of the Breast. Lyon, France: IARC; 2012

25. Edge SB, Byrd DR, Compton CC, Fritz AG, Greene FL, Trotti A: AJCC Cancer Staging Manual. 7th edition. New York: Springer; 2009.

26. Allred D, Harvey JM, Berardo M, Clark GM: Prognostic and predictive factors in breast cancer by immunohistochemical analysis. Mod Pathol 1998, 11:155.

27. Kim JR, Moon YJ, Kwon KS, Bae JS, Wagle S, Yu TK, Kim KM, Park HS, Lee J-H, Moon WS: Expression of SIRT1 and DBC1 Is Associated with Poor Prognosis of Soft Tissue Sarcomas. PloS one 2013, 8:e74738.

28. Moon WS, Jang KY, Chung MJ, Kang MJ, Lee DG, Lee H, Park HS: The expressions of nerve growth factor and its receptor p75NGFR in hepatocellular carcinoma: their relation with the clinicopathologic factors. Korean J Pathol 2009, 43:145-151.

29. Descamps S, Lebourhis X, Delehedde M, Boilly B, Hondermarck H: Nerve growth factor is mitogenic for cancerous but not normal human breast epithelial cells. J Biol Chem 1998, 273:16659-16662.

30. Demont Y, Corbet C, Page A, Ataman-Önal Y, Choquet-Kastylevsky G, Fliniaux I, Le Bourhis X, Toillon R-A, Bradshaw RA, Hondermarck H: Pro-nerve growth factor induces autocrine stimulation of breast cancer cell invasion through tropomyosin-related kinase $A(T r k A)$ and sortilin protein. J Biol Chem 2012, 287:1923-1931.

31. Bassili M, Birman E, Schor NF, Saragovi HU: Differential roles of Trk and p75 neurotrophin receptors in tumorigenesis and chemoresistance ex vivo and in vivo. Cancer Chemother Pharmacol 2010, 65:1047-1056.

32. Tsang JY, Wong KH, Lai MW, Lacambra MD, Ko C-W, Chan SK, Lam CC, Alex M, Tan P-H, Gary MT: Nerve growth factor receptor (NGFR): a potential marker for specific molecular subtypes of breast cancer. J Clin Pathol 2013, 66:291-296.

33. Siegel R, Naishadham D, Jemal A: Cancer statistics, 2013. CA Cancer J Clin 2013, 63:11-30.

34. Geyer CE, Forster J, Lindquist D, Chan S, Romieu CG, Pienkowski T, Jagiello-Gruszfeld A, Crown J, Chan A, Kaufman B, Skarlos D, Campone M, Davidson N, Berger M, Oliva C, Rubin SD, Stein S, Cameron D: Lapatinib plus capecitabine for HER2-positive advanced breast cancer. N Engl J Med 2006, 355:2733-2743.

35. Marty M, Cognetti F, Maraninchi D, Snyder R, Mauriac L, Tubiana-Hulin M, Chan S, Grimes D, Anton A, Lluch A, Kennedy J, O'Byrne K, Conte P, Green M, Ward C, Mayne K, Extra JM: Randomized phase II trial of the efficacy and safety of trastuzumab combined with docetaxel in patients with human epidermal growth factor receptor 2-positive metastatic breast cancer administered as first-line treatment: the M77001 study group. J Clin Oncol 2005, 23:4265-4274.

36. Romond EH, Perez EA, Bryant J, Suman VJ, Geyer CE Jr, Davidson NE, Tan-Chiu E, Martino S, Paik S, Kaufman PA, Swain SM, Pisansky TM, Fehrenbacher L, Kutteh LA, Vogel VG, Visscher DW, Yothers G, Jenkins RB, Brown AM, Dakhil SR, Mamounas EP, Lingle WL, Klein PM, Ingle JN, Wolmark N: Trastuzumab plus adjuvant chemotherapy for operable HER2-positive breast cancer. N Engl J Med 2005, 353:1673-1684.

37. Tagliabue E, Castiglioni F, Ghirelli C, Modugno M, Asnaghi L, Somenzi G, Melani C, Menard S: Nerve growth factor cooperates with p185(HER2) in activating growth of human breast carcinoma cells. J Biol Chem 2000, 275:5388-5394.

38. Bahmani P, Hassanshahi G, Halabian R, Roushandeh AM, JahanianNajafabadi A, Roudkenar MH: The expression of heme oxygenase-1 in human-derived cancer cell lines. Iran J Med Sci 2011, 36:260-265.

39. Berberat PO, Dambrauskas Z, Gulbinas A, Giese T, Giese N, Kunzli B, Autschbach F, Meuer S, Buchler MW, Friess $\mathrm{H}$ : Inhibition of heme oxygenase- 1 increases responsiveness of pancreatic cancer cells to anticancer treatment. Clin Cancer Res 2005, 11:3790-3798.

40. Sunamura M, Duda DG, Ghattas MH, Lozonschi L, Motoi F, Yamauchi J, Matsuno S, Shibahara S, Abraham NG: Heme oxygenase-1 accelerates tumor angiogenesis of human pancreatic cancer. Angiogenesis 2003, 6:15-24.

41. Miyake M, Fujimoto K, Anai S, Ohnishi S, Kuwada M, Nakai Y, Inoue T, Matsumura Y, Tomioka A, Ikeda T, Tanaka N, Hirao Y: Heme oxygenase-1 promotes angiogenesis in urothelial carcinoma of the urinary bladder. Oncol Rep 2011, 25:653-660.

42. Gueron G, De Siervi A, Ferrando M, Salierno M, De Luca P, Elguero B, Meiss R, Navone N, Vazquez ES: Critical role of endogenous heme oxygenase 1 as a tuner of the invasive potential of prostate cancer cells. Mol Cancer Res 2009, 7:1745-1755.

43. Hill M, Pereira V, Chauveau C, Zagani R, Remy S, Tesson L, Mazal D, Ubillos L, Brion R, Asghar K, Mashreghi MF, Kotsch K, Moffett J, Doebis C, Seifert M, Boczkowski J, Osinaga E, Anegon I: Heme oxygenase-1 inhibits rat and human breast cancer cell proliferation: mutual cross inhibition with indoleamine 2,3-dioxygenase. FASEB J 2005, 19:1957-1968.

44. Lin CW, Shen SC, Hou WC, Yang LY, Chen YC: Heme oxygenase-1 inhibits breast cancer invasion via suppressing the expression of matrix metalloproteinase-9. Mol Cancer Ther 2008, 7:1195-1206.

45. Was H, Sokolowska M, Sierpniowska A, Dominik P, Skrzypek K, Lackowska B, Pratnicki A, Grochot-Przeczek A, Taha H, Kotlinowski J, Kozakowska M, Mazan A, Nowak W, Muchova L, Vitek L, Ratajska A, Dulak J, Jozkowicz A: Effects of heme oxygenase- 1 on induction and development of chemically induced squamous cell carcinoma in mice. Free Radic Biol Med 2011, 51:1717-1726.

doi:10.1186/1471-2407-13-516

Cite this article as: Noh et al:: Expression of nerve growth factor and heme oxygenase- 1 predict poor survival of breast carcinoma patients. BMC Cancer 2013 13:516. 